\title{
GIS BASED IRRIGATION WATER MANAGEMENT
}

\author{
Avinash Kumar', O.P.Dubey ${ }^{2}$, S.K.Ghosh ${ }^{3}$ \\ ${ }^{1}$ Geomatics Engineering Group, Department of Civil Engineering, Indian Institute of Technology, Roorkee \\ ${ }^{2}$ Geomatics Engineering Group, Department of Civil Engineering, Indian Institute of Technology, Roorkee \\ ${ }^{3}$ Geomatics Engineering Group, Department of Civil Engineering, Indian Institute of Technology, Roorkee
}

\begin{abstract}
The objective of this paper is to project the prospects of Geographical Information System (GIS) in irrigation water management. Precise assessment, analysis and management of irrigation water in spatial temporal domain can be efficiently carried out by proper blending of GIS techniques. Estimation of irrigation water requirement from a farm level to regional scale is possible due to the management and spatial analysis capabilities of GIS. Conglomeration of GIS helps in precise management of water for irrigation and producing more crops per drop of water.
\end{abstract}

Keywords - GIS, Irrigation water management, spatially distributed database, Remote sensing

\section{INTRODUCTION}

India serves $18 \%$ of world population with only $2.4 \%$ of world geographical area along $4 \%$ of world's renewable water resource. The expected population by 2025 is around 1390 million. In order to cater to the growing population, food production has to be raised from 208 million tons in year 1999-2000to 350 million ton by 2025 (MoWR, 2012). Present water use in agriculture sector is about $83 \%$ of total water use and it is likely to go down by $10-20 \%$ by 2025 for fulfilling the increasing domestic and industrial needs. Thus there is a need to improve in management and utilization of water resource to achieve more crop per drop of water to fulfil the demand of food for the increasing population. Lot of work has been carried out regarding computation of irrigation water requirement based upon soil type, climatic condition and water distribution. Spatially distribution of above information and its complex effect has lead to the usage of Geographical Information System (GIS) and other technologies to this field. The aim of this paper is to explore the possible use of GIS in the area of irrigation water management.

\section{IRRIGATION WATER MANAGEMENT}

Recent studies show that at present water use in agriculture sector in India is approximately $605 \times 109 \mathrm{~m} 3$, which is $83 \%$ of total water use and it is likely to go down by $10-20 \%$ by 2025 for fulfilling the increasing domestic and industrial needs (Choudhary, 1995, GOI 2008).

\subsection{Irrigation Water}

Irrigation can be defined as artificial supply of water to soil for raising crop. Irrigation is necessary due to inappropriate rainfall, non uniform rainfall, growing a number of crops during a year, growing perennial crops, commercial crops with additional water, controlled water supply. Irrigation requirement of crops differs from one area to another due to varying climatic and soil characteristic of different agroclimatic zone. Estimation of optimal requirement of water (water supplied by precipitation as well as water delivered by irrigation) for a crop is indispensable for getting maximum yield with economical use of water. Management of water is required for getting more crops per drop of water.

\subsection{Irrigation Water Management}

Irrigation water management is done by determining suitable frequency and duration of watering based upon available water. The crop water requirement is also influenced by the following factors, such as:

i) soil and land i.e. type of soil, its texture, permeability and infiltration, sub soil water table, slope of the ground and drainage conditions.

ii) climatologyi.e. rainfall, its amount, intensity and its distribution, temperature, wind movement, relative humidity.

iii) crops grown i.e.type of crops, density and depth of rooting, rate of root growth, tolerance to climatic changes and varietal effects.

iv) agricultural practices i.e.type of irrigation system adopted, intensity of irrigation adopted, type and quantity of fertilizer used, and other cultural practices.

v) Socio economic characteristicsi.e. socio economic characteristics of farmers influence irrigation requirements.

Development of appropriate an irrigation scheduling requires information such as:

i) Soil texture,

ii) Water holding capacity of soil,

iii) Soil moisture content,

iv) Crop water requirement at the specific development stage.

\subsection{Current Issues in Irrigation Water Management}

i) There are certain issues which need consideration in implementation of an appropriate irrigation 
scheduling in India. The present trend of irrigation has caused $25 \%$ depletion in ground water reserve by 2010. Studies shows that there is an increasing trend in demand of water in irrigation, which may lead to total depletion of the ground water table within 50 years (Alawi and Abdulrazzak, 1994). Some existing issues in irrigation scheduling are:

ii) Higher initial implementation and operational cost,

iii) Requirement of skilled personal,

iv) Lack of coordination between the farmers and the Irrigation scheduling personal,

v) Uncertainty of data (quantity of available and required water during irrigation events) is one of the biggest problems associated with irrigation scheduling,

vi) Lack of awareness in farmers as they are mostly poor and illiterate,

vii) Irrigation scheduling methods has been developed but not yet transferred to the farmer's field.

However, it is observed that irrigation scheduling techniques lacks in:

i) Availability of data

ii) Reliability of data

iii) Timely availability of data

These problems can beresolved by adopting GIS and other data such as remote sensing data.

\section{GIS}

GIS is "an organized compilation of database, application, hardware, software, and trained manpower competent of capturing, manipulating, organization, and analyzing the spatially reference database and production of output both in tabular and map form." Major tasks performed by the GIS are shown in Fig. 1

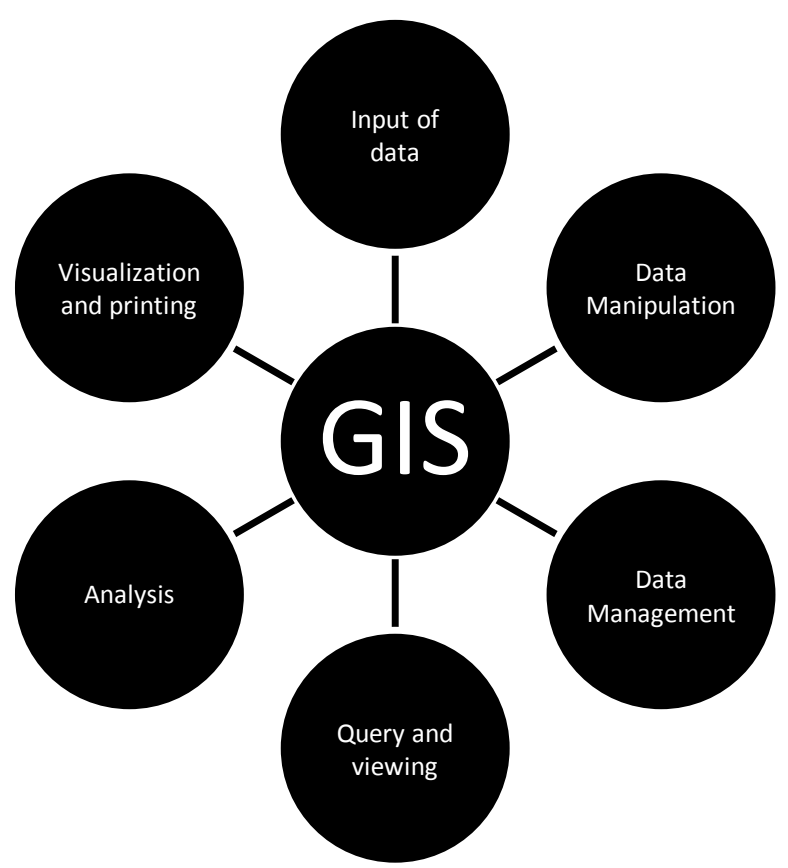

Fig 1 Major tasks in GIS
Input of data by digitization of paper maps by scanning and vector processing, classification of image.

Data Manipulation such that all information are transformed into same scale and geo-referenced before integration.

Data Management using spatial and attribute database. Query and Viewing of data to provide answers from database any query such as length, area, volume or location of an information(s).

Analysis of data to generate different scenario based on different criteria such as water scarcity in a particular area, intensity or severity of rainfall on crop in a given area.

Visualization and printing of maps of defined information in printable format having all the information required for by end user.

\section{GIS DATA TYPES}

Geographical data are numerical representation of the real world in digital form. Geographic database is organized digital geographic data. The types of Geographical data are shown in Fig. 2

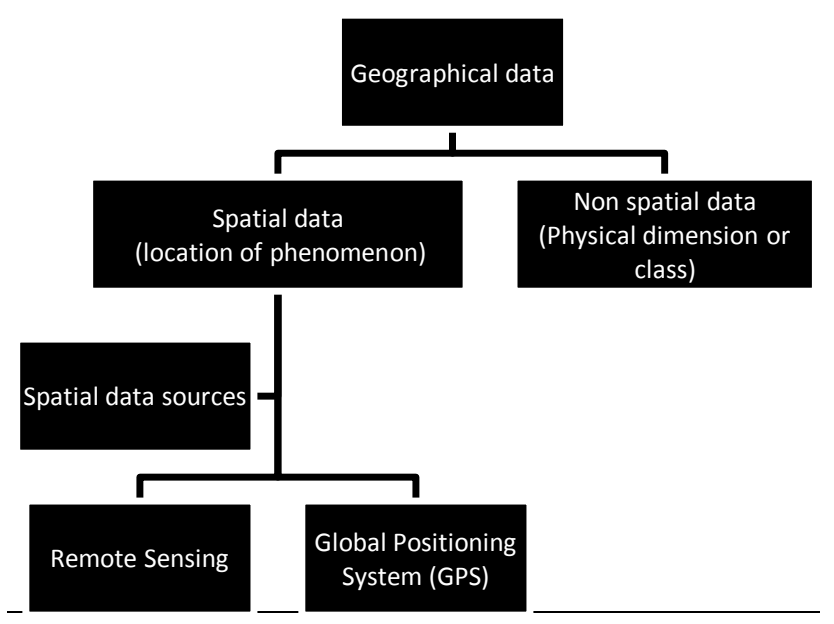

Fig. 2 GISInput data type

Remote Sensing data provides information regarding the earth surface features in the form of reflected electromagnetic energy. Since the satellite has the capability to revisit an area at defined intervals, thus temporal data can be used to identify any change which may occur during this revisit interval. Further, satellite is available both in hard copy and digital form, hence digital based analysis provide consistent results in raster format.

Global positioning system is a network of navigational satellite which provides terrestrial position and tracking of moving object. The data is in vectorformat as it is in point form. The spatial data is stored as coordinate pair. Appropriate projection system for storing the geographic feature in 2D coordinate system is required. Specifying a common coordinate system for the database is required for the development of database in GIS. 


\section{APPLICATION OF GIS}

i) GIS can be used in variety of domains such as agriculture, management of natural resource, urban and rural planning, marketing/development of business, Crime analysis, utility mapping and management. Applicability of GIS in the field of agriculture and management of water resource are:

ii) Agro-climatic factor affecting crop growth

iii) Soil database for efficient management

iv) Agro climatic crop suitability

v) Crop hazard and yield modelling

vi) Assessment of agro climatic characteristics

vii) Crop suitability analysis

viii) Precise agriculture

ix) Farmers training school

$x$ Agriculture management research

xi) Development planning of agriculture

xii) Spatial map for hydraulic properties of soil

xiii) Ground water depth table map

xiv) Water demand map by estimation of crop water stress

$x v$ Irrigation scheduling

$x v i) \quad$ Estimating water logging condition

xvii) Large scale irrigation system management and supporting decision making processes by spatially distributed data sets.

These application of GIS helps in management of water for irrigation more efficiently and effectively to achieve our goal of more crop per drop of water.

\subsection{GIS benefits over other Information System}

Making decision and answering question are the fundamental use of GIS. GIS also helps in collection, storage and analysis of objects and phenomena along with geographic location. Overlay of map/layers and spatial searching are the exclusive features of GIS such as crop potential map and canal maps when combined in GIS produces crop/land suitability map on temporal and spatial basis. Decision making in agriculture requires data on soil, land, climate, crop and hydrology. Physical computation and manipulation of these data is complex and time consuming. For resource managers and decision makers GIS is an advanced and excellent planning tool. GIS plays vital role in configuration of modern information technology.

\subsection{GIS in Management of Water for Irrigation}

GIS helps in generation of irrigation water demand map by modelling of water demand considering variation in crop, soil and climate. Estimation of regional irrigation water as explained in Fig. 3 requires geo-referenced database and map of climate, crop, soil, canal network and its command area. The computation algorithm for effective rainfall, evapo-transpiration (ET), crop coefficient, percolation application efficiency, water conveyance efficiency, cropping pattern distribution is get computed by the help of database, which ultimately helps in calculating crop water requirement and finally irrigation water requirement. GIS helps in preparing the effective schedule based on available water for irrigation

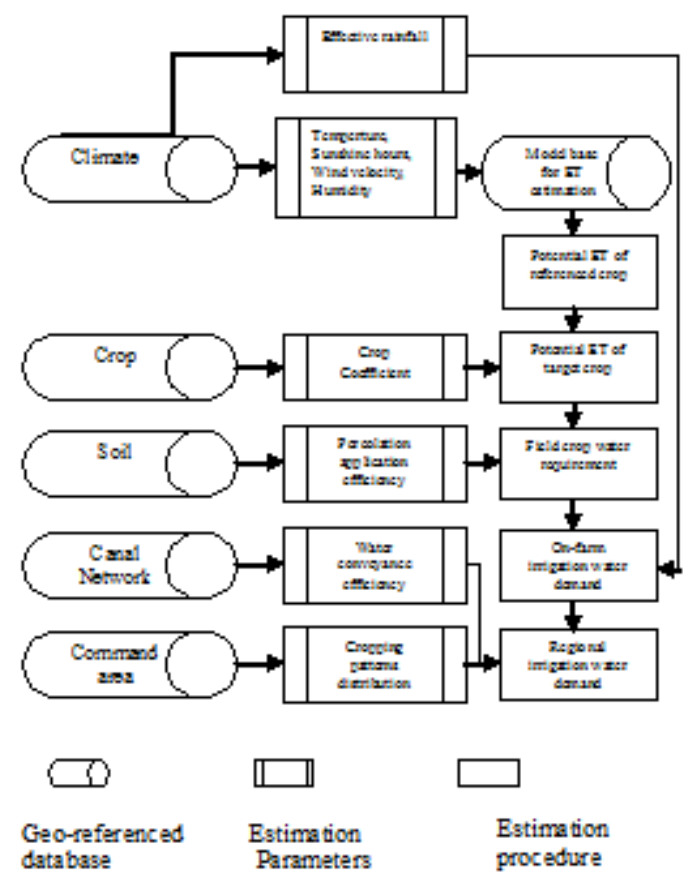

Fig. 3 Estimation of regional water demand for irrigation

\section{CONCLUSIONS}

The following conclusion can be drawn after the study of irrigation scheduling using remote sensing data:

i) Irrigation water management is a complex task since it depends upon various factors such as climate data, soil type data and rainfall data.The efficiency depends upon the reliability of these data.

ii) Remotely sensing is capable of providing reliable and accurate data which are useful in GIS based analysis.

iii) Remote sensing and GPS with integration of GIS provides remarkable advantages for irrigated area mapping with enhanced dependable analysis at various temporal and spatial scales.

iv) GIS with appropriate blending of remote sensing helps in equitable use of water resource.

v) Currently, while calculating the water requirement a variety of factors are generally assumed (such as $\mathrm{K}_{\mathrm{c}}$, Albedo). These factors can be reliably estimated by synergistic use of remote sensing in GIS environment.

vi) Remote sensing and GIS integrated approach can be used for estimation of crop water requirement and irrigation water requirement.It also helps in getting maximum yields with optimum water use which ultimately causes more savings.

vii) Integration of remote sensing data with ground data in GIS provide efficient estimation of major crops, area under each crop and variation in water demand of different crops in irrigation scheduling. 
viii) GIS and remote sensing in irrigation scheduling is time and cost effective.

\section{REFERENCES}

[1] Alawi Al, J. and Abdulrazzak, M. (1994). Water in the Arabian Peninsula: Problems and perspective, Ed. Peter Rogers and Peter Lydon, Harvard University Press pp.171-202

[2] Choudhary, T.N., 1995. Water management: issues and strategies. J. Indian Sco. Soil Sci. 43 (4), 537541.

[3] GoI, 2008, XI Five Year Plan, Planning Commission, Government of India, New Delhi.

[4] Ministry of Water Resources, 2012. National Water Policy. Ministry of Water Resources, Government of India,New Delhi. 